\title{
Corpus-Based Vocabulary Analysis of Rock Guitar Lessons and a Sample Dictionary
}

\author{
Nantakarn Impong and Jirapa Vitayapirak
}

\begin{abstract}
This study explored in-depth to the language of rock guitar lessons. The aims of this study are to find out terminologies used in rock guitar lessons and to design a sample bilingual dictionary for Thais. The user needs analysis was done to receive information about reading materials to compile the Rock Guitar Lessons Corpus (RGL). The RGL Corpus consists of $1,356,029$ words (tokens). The concordance software "Wordsmith Tools", and "RANGE_GAL_AWL Programs" were used.

The word lists were classified into three groups of general, academic, and technical vocabularies. The function words, content words, collocation, and abbreviations were also analyzed. The total word types in the corpus were 40,542 and the types and tokens ratio was $1: 33.44$. The results showed that general vocabulary occurred at the highest frequency. Some general and academic words were used as technical terms. Many multi-word terms were frequently found when using KWIC concordance. These terms were formed by combination of general and academic vocabularies. Symbols and abbreviations were significantly found in the corpus, i.e. clippings, initials, acronyms, contractions, and substitutions. The word frequencies, word combination and typical usage were used to create sample English-Thai dictionary entries of rock guitar.
\end{abstract}

Index Terms-Corpus, rock guitar, dictionary, vocabulary, terminology, KWIC concordance.

\section{INTRODUCTION}

Rock music is a kind of music which is popular in the world and Thai society. It started in Thai society in the period of Vietnam War (1964-1972) due to the United States of America sending troops to Vietnam using Thailand as the military base in 1964 . There were many US army camps around Thailand. One of the famous entertainment during the war period for the American soldiers was string music bands in the bar and night club. Western popular music was usually played to serve the American soldiers and started to be popular among the Thai musical audience. The electric guitar is the major instrument in rock music and it has been popular from then onto the present.

At present, rock music is very popular in Thailand. There are many multimedia like teaching guitar through the videos, guitar books and also various English music notes. They were launched to whoever was interested in playing rock music [1]. Many academic institutions in Thailand such as

Manuscript received September 1, 2014; revised January 23, 2015.

Nantakarn Impong is with the Dept. of Applied Linguistics (English for Science and Technology), King Mongkut's Institute of Technology, Ladkrabang, Thailand (e-mail: Modrockguitar@gmail.com).

Jirapa Vitayapirak is with the Dept. of Applied Arts (English), Faculty of Industrial Education, King Mongkut's Institute of Technology, Ladkrabang, Thailand (e-mail: kvjirapa@kmitl.ac.th).
College of Music, Mahidol University, Silpakorn University and Rangsit University include the electric guitar into their curriculum. According to Thai university library statistics in the year 2012, there are many guitar references or dictionaries of music written in English. However, very few references about rock music were written in Thai. It is difficult for Thai musicians to clearly understand the rock guitar terms. Therefore, this study aims to investigate the important vocabularies and compile a bilingual (EnglishThai) rock guitar dictionary for Thai students who love playing rock guitar. As [2] stated that the dictionary is a part of vocabulary learning. For foreign learners of English like Thais, they should be encouraged to avail themselves of the substantial information contained in their dictionary.

The rock guitar terms are a specialized form of natural language used to describe a limited subject matter or a sublanguage, generally employed by a group of specialists among guitar players dealing with rock music. According to [3], the set of sentences in a sublanguage is a subset of the sentences in a whole language [4]. Most guitar players always use the sublanguages in terms of specific terminology such as ARPEGGIO, PENTATONIC SCALE, MELODIC MINOR SCALE, and so on in their community.

According to [5], the English vocabulary in academic text can be divided into three categories: General Service List (GSL) or high frequency words, academic vocabulary (AWL), and Off-list words (including technical and low frequency words). On average, the GSL and AWL vocabulary represent approximately $90 \%$ of running words in academic text. The technical vocabulary covers around 5\% and the other low frequency words such as proper name, abbreviation, and numbers represents around 5\% of the total words in the text.

In Thailand, there have been no previous studies about the vocabulary levels of rock guitar, especially the technical vocabulary. This research thus focuses on compiling corpus to findout rock guitar terminologies. A corpus is a large body of machine - readable texts and a collection of linguistic data, either compiled as written texts or as a transcription of recorded speech [6], [7] found that corpusbased study is another way to use computer readable forms in doing the linguistic research with less effort. It has many advantages in usingcomputer readable such as finding, classifying, retrieving, and calculating data with high speed. The corpus-based analysis has also never been used for analyzing rock guitar lessons. Therefore, this study used corpus-based analysis to study rock guitar lesson texts and lead to design a sample dictionary of rock guitar lessons.

\section{OBJECTIVES}

1) To analyze technical vocabulary used in rock guitar 
lessons.

2) To identify abbreviations and symbols found in rock guitar lessons.

3) To examine collocations found in rock guitar lessons.

4) To design a sample dictionary entries based on the technical vocabularies found in the corpus.

\section{MATERIALS AND METHODS}

\section{A. Data Collection}

The surveys of rock guitar lessons in the top ten leading Universities in music education were used to elicit information about the English guitar lessons that they encountered and these selected lessons were used to compile the RGL corpus.

Three hundred rock guitar lessons from guitar magazines and guitar instruction books during the year 2009-2013were collected as a sample in this study. In other words, the 150 rock guitar lessons from guitar magazines and 150 rock guitar lessons from guitar instruction books were selected. The weighting of two samples is equal because both of them are equally used among guitar players.

\section{B. Research Instruments}

In this study selected three instruments: Wordsmith Tools Version 6.0 [8], RANGE_GAL_AWL Programs by [9] and AntConc 3.4 .3 by [10]. The first program used was Wordsmith Tools Version 6.0. It was used to analyze basic statistics of word analysis in terms of types, tokens, word frequency and concordance. The second program used was RANGE_GAL_AWL Programs. It was used to calculate the vocabulary levels: General vocabulary, Academic vocabulary, Off-list words refer to Technical vocabulary, Abbreviation, and Symbols. The last program used was AntConc 3.4.3. It was used to calculate compounds and multiword terms.

\section{Data Analysis}

In this study, the Wordlist, cluster and concordance tools were used to generate lists in frequency order for lexical comparison of texts. In data processing, the frequency and distribution of word types and tokens in the RGL Corpus were first determined. Since the focus of this research was on the terminologies. In order to find out important terms, the three word types, i.e. general (GSL), academic (AWL), and off-list words were analyzed by using RANGE_GAL_AWL Programs. Then, the abbreviations, symbols, and collocation were identified.

\section{RESUlTS AND DisCUSSION}

\section{A. Statistical Analysis of the RGL Corpus}

Table I below shows the statistics or the output of the lexicon extraction program, showing the size of the lexicon produced from the RGL Corpus.

Statistics can provide various kinds of summary of the contents of the RGL corpus. They can show the Type/Token ratio of the whole vocabulary, which is computed by dividing the number of the tokens by the number of types. It indicates the relative concentration or dispersion of the vocabulary, and offers a measure of its diversity. The lower of type-token ratio, the greater the diversity of words in the corpus.

\begin{tabular}{lr}
\multicolumn{2}{l}{ TABLE I: STATISTIC LISTS IN THE RGL CORPUS } \\
\hline \hline Text file & \multicolumn{1}{c}{ Overall } \\
\hline file size & $14,465,223$ \\
\hline tokens (running words) in text & $1,356,029$ \\
\hline tokens used for word list & $1,158,603$ \\
\hline sum of entries & \\
\hline types (distinct words) & 40,542 \\
\hline type/token ratio (TTR) & 3.50 \\
\hline standardized TTR & 31.76 \\
\hline STTR std.dev. & 66.62 \\
\hline STTR basis & 1,000 \\
\hline mean word length (in characters) & 3.54 \\
\hline Word length std.dev. & 2.47 \\
\hline sentences & 90,564 \\
\hline mean (in words) & 14.70 \\
\hline std.dev. & 573.84 \\
\hline paragraphs & 140 \\
\hline mean (in words) & $8,275.74$ \\
\hline std.dev. & 20,862 \\
\hline \hline
\end{tabular}

TABLE II: TOKENS AND WORD TYPES IN THE RGL CORPUS

\begin{tabular}{ll}
\hline \hline Tokens & $1,356,029$ \\
\hline Word types & 40,542 \\
\hline Type/token ratio & $1: 33.44$ \\
\hline \hline
\end{tabular}

In Table II the overall corpus size comprised of $1,356,029$ tokens or running words. The total number of word types equals 40,542 words in the corpus since a recurrent word is counted only once. For the whole corpus, the ratio of types/tokens is $1: 33.44$. The ratio indicated that each word was repeated nearly 34 times on average throughout the corpus.

\section{B. Vocabulary Levels}

It was found out that the three types of vocabulary used in the rock guitar lesson corpus were $13.7 \%$ of general vocabulary, $10.5 \%$ of academic vocabulary and $75.8 \%$ of off-list words. The off-list words could be divided into $8.32 \%$ of technical vocabulary, $44.6 \%$ of abbreviations, and $22.87 \%$ of symbols as shown in Fig. 1 below:

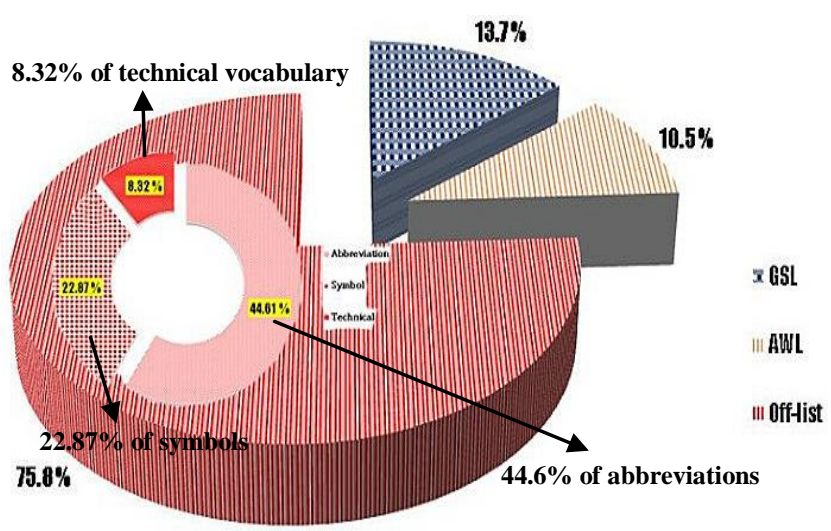

Fig. 1. Proportion of general, academic, and off-list vocabularies.

This finding did not align itself closely with the figures 
cited by [5], [9] that on average, the GSL and AWL vocabulary represent approximately $90 \%$ of running words in academic text. The technical vocabulary covers around 5\% and the other low frequency words such as proper name, abbreviation, and numbers represents around $5 \%$ of the total words in the text. We can see that the rock guitar lesson is a text-type that covers a large amount of off-word lists, i.e. abbreviations, symbols, and technical terms.

In terms of word classes, two major types of word classes, namely function words and content words were found in the corpus. The function words were found at the top ten word frequency lists in the RGL Corpus such as 'THE', 'A', 'AND', 'TO', 'OF', and 'IT'. Interestingly, abbreviations such as 'I', 'L', 'E' occurred in high frequency as well, as shown in Table III below:

TABLE III: THE TOP 10 WORD FREQUENCY LISTS IN THE RGL CORPUS

\begin{tabular}{llll}
\hline \hline Rank & Word & Frequency & \% of occurrence \\
\hline 1. & THE & 55,214 & 4.07 \\
\hline 2. & I & 52,844 & 3.90 \\
\hline 3. & A & 32,138 & 2.37 \\
\hline 4. & AND & 22,677 & 1.67 \\
\hline 5. & TO & 21,073 & 1.55 \\
\hline 6. & OF & 18,896 & 1.39 \\
\hline 7. & IN & 16,817 & 1.24 \\
\hline 8. & L & 15,095 & 1.11 \\
\hline 9. & YOU & 13,313 & 0.98 \\
\hline 10. & E & 11,860 & 0.87 \\
\hline \hline
\end{tabular}

\section{Content Words}

Content words are those that belong to the large, open classes of the language including: noun, verbs, adjectives, and adverbs.

Table IV shows the ten most frequent content words found in the RGL corpus:

TABLE IV: THE TOP 10 CONTENT WORDS IN THE RGL CORPUS

\begin{tabular}{lllll}
\hline \hline No. & Rank & Words & Freq. & \% \\
\hline 1. & 19 & GUITAR & 7,180 & 0.53 \\
\hline 2. & 29 & CHORD & 5,456 & 0.40 \\
\hline 3. & 37 & MAJOR & 4,628 & 0.34 \\
\hline 4. & 38 & BLUES & 4,627 & 0.34 \\
\hline 5. & 40 & SCALE & 4,361 & 0.32 \\
\hline 6. & 41 & MINOR & 4,324 & 0.32 \\
\hline 7. & 44 & STRING & 3,832 & 0.28 \\
\hline 8. & 45 & CHORDS & 3,809 & 0.28 \\
\hline 9. & 47 & NOTE & 3,767 & 0.28 \\
\hline 10. & 55 & NOTES & 3,600 & 0.27 \\
\hline \hline
\end{tabular}

For a dictionary of Rock Guitar, we shall be concentrating on high frequency nouns among content words. As shown in Table III, general words of music appeared at the high frequency such as 'GUITAR' $(7,180$ times), 'CHORD' (5,456 times), 'MAJOR' (4,628 times), 'BLUES' (4,627 times), and so on.

\section{Compounds and Multiword Terms}

The RGL concordances show that most of the nouns are compounds and multiword terms. Most of them consist of nouns, with proceeding nouns functioning as adjectives, e.g. blues guitar, chord progression, bar blues, etc. We can see that although there are two or more lexemes, the parts function as a single item, with its own meaning. Table V below shows the top ten compounds in the rock guitar lesson corpus that were chosen from the highest frequency of clusters.

TABLE V: THE TOP 10 COLLOCATIONS IN THE RGL CORPUS

\begin{tabular}{|c|c|c|c|}
\hline No. & Word (Freq.) & Collocations & Frequency \\
\hline 1. & $\begin{array}{c}\text { GUITAR } \\
(7,180)\end{array}$ & BLUES GUITAR & 1,053 \\
\hline 2. & $\begin{array}{l}\text { CHORD } \\
(5,456)\end{array}$ & CHORD PROGRESSION & 369 \\
\hline 3. & $\begin{array}{l}\text { MAJOR } \\
(4,628)\end{array}$ & MAJOR SCALE & 1,317 \\
\hline 4. & $\begin{array}{r}\text { BLUES } \\
(4,627)\end{array}$ & BAR BLUES & 540 \\
\hline 5. & $\begin{array}{l}\text { SCALE } \\
(4,361)\end{array}$ & MAJOR SCALE & 904 \\
\hline 6. & $\begin{array}{l}\text { MINOR } \\
(4,324)\end{array}$ & MINOR SCALE & 449 \\
\hline 7. & $\begin{array}{c}\text { STRING } \\
(3,832)\end{array}$ & E STRING & 119 \\
\hline 8. & $\begin{array}{c}\text { CHORDS } \\
(3,809)\end{array}$ & POWER CHORDS & 175 \\
\hline 9. & $\begin{array}{l}\text { NOTE } \\
(3,767)\end{array}$ & EIGHT NOTE & 114 \\
\hline 10. & $\begin{array}{l}\text { NOTES } \\
(3,600)\end{array}$ & QUARTER NOTES & 55 \\
\hline
\end{tabular}

\section{E. Technical Vocabularies}

In terms of technical vocabularies with high frequency in RGL corpus, the terms such as 'PENTATONIC' (1,496 times), 'ARPEGGIO' (850 times), and 'HARMONIC'(848 times) appeared at the high frequency as shown in Table VI below:

TABLE VI: THE TOP 10 TECHNICAL VOCABULARIES IN THE RGL CORPUS

\begin{tabular}{lllll}
\hline No. & Rank & Words & Freq. & $\%$ \\
\hline 1. & 111 & PENTATONIC & 1,496 & 0.11 \\
\hline 2. & 173 & ARPEGGIO & 850 & 0.06 \\
\hline 3. & 174 & HARMONIC & 848 & 0.06 \\
\hline 4. & 210 & MELODIC & 679 & 0.05 \\
\hline 5. & 214 & DIMINISHED & 664 & 0.05 \\
\hline 6. & 271 & DOMINANT & 511 & 0.04 \\
\hline 7. & 318 & MODES & 437 & 0.03 \\
\hline 8. & 332 & TAPPING & 422 & 0.03 \\
\hline 9. & 369 & DORIAN & 379 & 0.03 \\
\hline 10. & 371 & CHROMATIC & 377 & 0.03 \\
\hline \hline
\end{tabular}

When observing in-depth about the nature of the specific language of rock guitar lessons, those words do not stand alone. They frequently occurred with other words such as the word 'PENTATONIC' always collocates with the word 
'SCALE' (PENTATONIC SCALE) and used as a compound noun. ARPEGGIO always collocates with the word 'MAJOR' or 'G MAJOR'. It is used as the multi-word terms such as 'G major arpeggio' as shown in KWIC concordance as in Fig. 2 below.
For the study of collocation, KWIC concordance is an excellent tool to help finding out the specific collocation of terms or technical vocabularies used in playing rock guitar. Fig. 3 shows the sample of collocation of the word 'MINOR' as 'melodic minor scale':

HING ROCK St BIUES GUIIRR BOOK Q nouns 9-z G-Major axpeggio, long fingering IRRCH $3{ }^{\prime} I ;+^{\prime}$ ?\# L. $-\$-J$ _ 4 : neck. Any combination of G, B, D will make a G-Major arpeggio. noun: 9-a is an unorthodox fingering that $\mathrm{g}$ you come up with nouns 12-11. Q noun: 12-10 BMajor axpeggio swept TRRCK S3 tr: 19- I- I J ' ij Ire I n D \$5 3: mun: 15-11 C-Major scale ascending, C-Major axpeggio descending $-5: ?$ IRHEK 9?, Ii) 5a5 IT:<;mI $+\sim$ ord 14. Dom7 (b9) Chord 15. Dom7 (\$9) Chord Dure Major Arpeggio Major 7 Arpeggio Major 6 Arpeggio Dure Minor hat you already know. For example, here is a $G$ major arpeggio based on the 6th- string root $G$ barre chord, on the 6 th- string root $G$ berre chord, and $a C$ major arpeggio based on the 5th-string root $C$ berre chord.

Fig. 2. KWIC Sample of collocation of the word 'G MAJOR ARPEGGIO' in the RGL corpus.

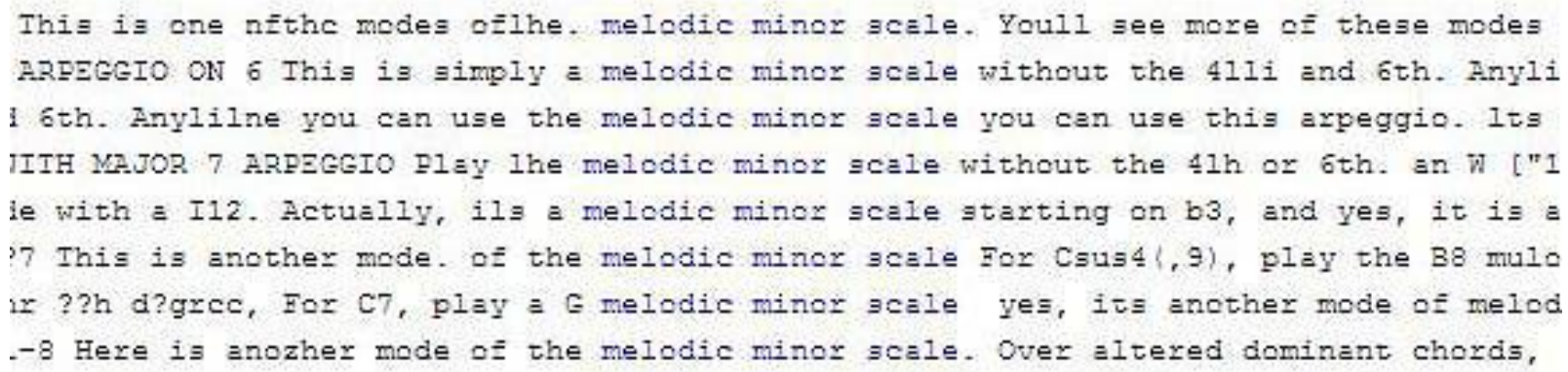

Table VII in below shows the high frequency technical noun phrases or multi-word lexical units taken from the top 20 high-frequency content words.

TABLE VII: TECHNICAL MULTI-WORD LEXICAL UNITS IN RGL CORPUS

\begin{tabular}{lll}
\hline \hline No. & $\begin{array}{l}\text { Technical Noun Phrases or Multi-Word } \\
\text { Lexical Units }\end{array}$ & Frequency \\
\hline 1. & MINOR PENTATONIC SCALE & 127 \\
\hline 2. & A MINOR PENTATONIC & 67 \\
\hline 3. & MINOR SCALE PATTERN & 66 \\
\hline 4. & C MAJOR SCALE & 65 \\
\hline 5. & MELODIC MINOR SCALE & 63 \\
\hline 6. & HARMONIC MINOR SCALE & 60 \\
\hline \hline
\end{tabular}

Regarding collocations, both lexical and grammatical collocations were found in this study. Most technical compounds and multi-word terms consisted of words from GSL, AWL, and technical vocabularies. From Fig. 3 and Fig. 4 , it can be seen that the words were not used in general sense but technical musical meaning such as 'melodic minor scale'.

\section{F. Abbreviations and Symbols}

Abbreviations were found frequently in the rock guitar lessons. In this study, we found many symbols and 5 main types of abbreviations, i.e. 1) clippings, 2) acronyms, 3) initialisms, 4) contractions, and 5) substitutions as shown in Table VIII below:
TABLE VIII: THE 10 HIGH-FREQUENCY ABBREVIATIONS IN RGL CORPUS

\begin{tabular}{lllll}
\hline No. & Words & Meaning & Freq. & \% \\
\hline 1. & E & E CHORD & 11,860 & 0.87 \\
\hline 2. & H & HAMMER ON & 10,403 & 0.77 \\
\hline 3. & F & F CHORD & 7,751 & 0.57 \\
\hline 4. & G & G CHORD & 7,528 & 0.56 \\
\hline $\mathbf{5 .}$ & M & MUTING & 7,441 & 0.55 \\
\hline 6. & T & TAPPING & 7,398 & 0.55 \\
\hline 7. & C & C CHORD & 7,046 & 0.52 \\
\hline 8. & S & SLIDE & 7,019 & 0.52 \\
\hline 9. & D & D CHORD & 5,791 & 0.43 \\
\hline $\mathbf{1 0 .}$ & B & BENDING & 5,035 & 0.37 \\
\hline \hline
\end{tabular}

The high frequency abbreviations include ' $E$ ' (E Chord11,860 times), ' $\mathrm{H}$ ' (Hammer on $-10,403$ times), and ' $F$ ' ( $F$ Chord - 7,751 times) and so on.

The top five high frequency symbols in RGL corpus are in Table IX below.

\section{G. The Corpus Inputs to the Dictionary}

The corpus is a primary source of information about the way words behave. It shows the frequency of words, grammatical information, and collocations. The main factor in deciding whether or not to include a word as an entry in the dictionary is how often it occurs in the corpus. The 
sample sentences from the concordance are the main sources of example sentences presented in the dictionary [11].

\section{1) Headword selection}

The information about the word frequency is very important for choosing or grading vocabularies. Therefore, the single words, compound words, multi-words, abbreviations and symbols with highest frequency were selected as the samples of rock guitar dictionary.

2) The design of a sample dictionary

An Entry Structure:

The entry 'Alternate Picking' below offers as a headword, pronunciation in Thai, Abbreviation, Thai synonym, Thai definition, example of English usage in a sentence taken from the concordance and illustration as shown in Fig. 4 below:

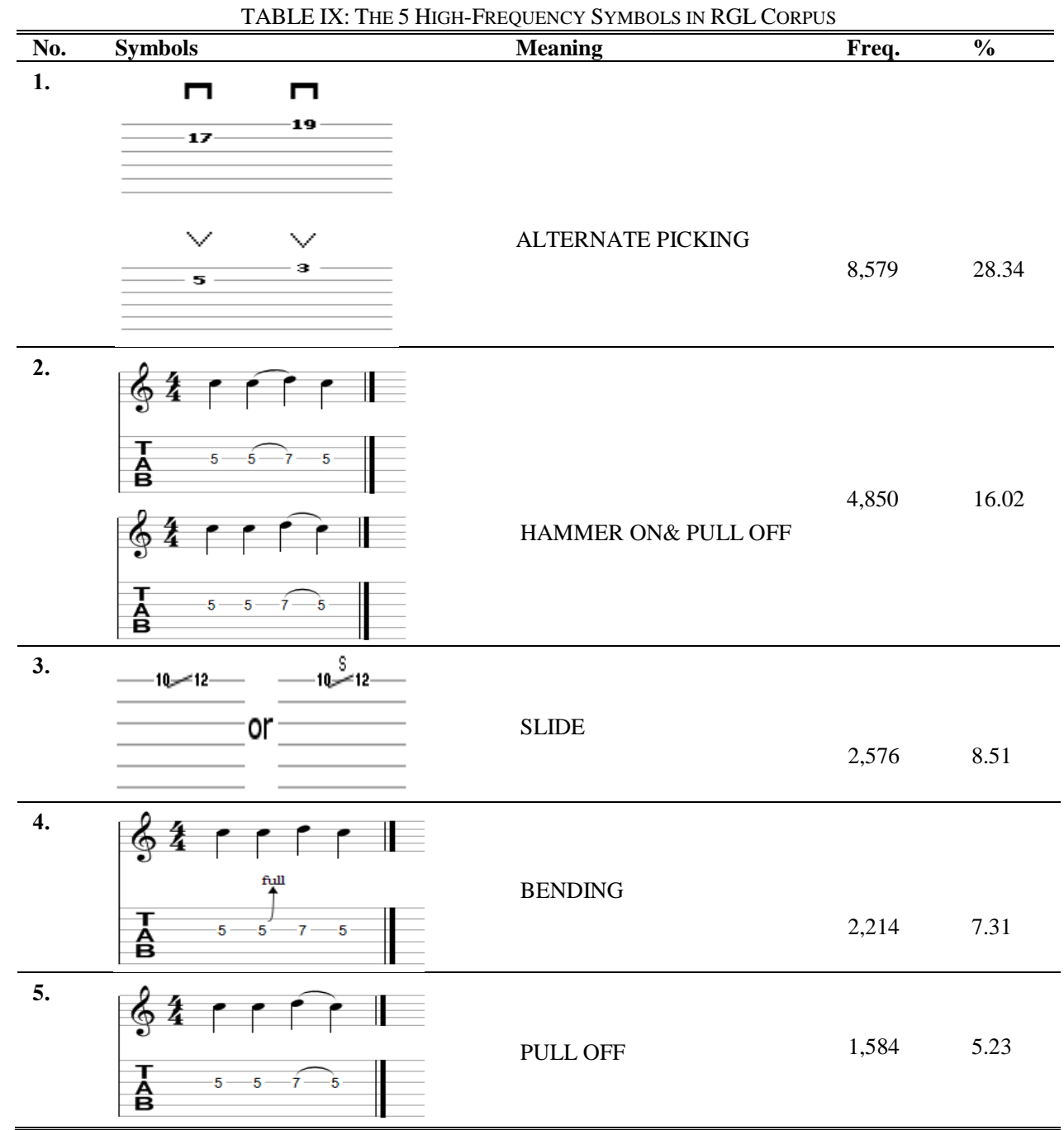

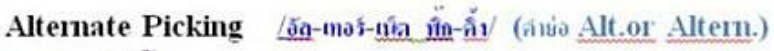

การถีลสลับปิ์ก

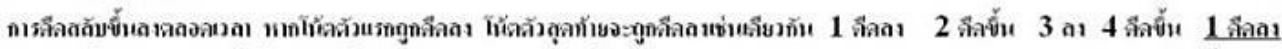

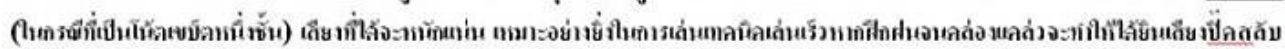
ข้ำเจย่าหั้ลเวน
\end{abstract}

Alternate picking is a big part of my guitar playing style.

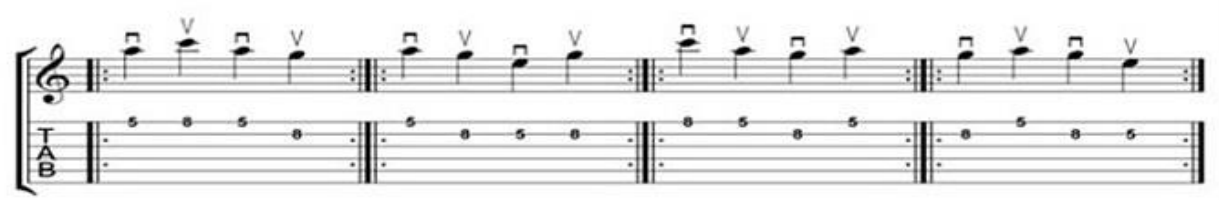

Fig. 4. The sample entry of RGL dictionary.

\section{CONCLUSION}

The purposes of this study were to compile a corpus of the Rock Guitar Lessons and analyze the word frequency lists, technical vocabularies, abbreviations, symbols, and collocations. The design of a sample rock guitar lesson dictionary was proposed. The results showed that there were $8.32 \%$ of technical terms in the RGL corpus. Some general 
and academic words were used as technical vocabularies. Many multi-word terms were frequently found in the texts when using KWIC concordance. Interestingly, symbols and abbreviations were significantly found in the RGL corpus, i.e. clippings, initials, acronyms, contractions, substitutions. The corpus findings on word frequencies, word combination and typical usage were used to create sample entries for the bilingual English-Thai dictionary of rock guitar. The findings thus have applications for a design of a rock guitar dictionary for musical students, musicians, guitar players, and those who are interested in playing rock guitar.

\section{ACKNOWLEDGEMENTS}

This work was supported in part by Thai Government Fellowship (SP2), Office of Vocational Education Commission. I would like to express my gratitude to Assoc. Prof. Dr. Jirapa Vitayapirak, my advisor, for her valuable suggestions and devotion of time in revising this paper. I would also like to thank Miss Piyanuch Charoen for her advice on software use, other suggestions and encouragement.

\section{REFERENCES}

[1] S. Wiwan, "Effect of Yngwie Malmsteen's guitar style on the Thai guitarists," M.A. thesis, Mahidol University, 2004.

[2] D. Summer, "The role of dictionary in language learning," in Vocabulary and Language Teaching, R. Carter and M. McCarthy, Eds. Longman, USA, 1988

[3] Z. Harris, Mathematical Structures of Language, New York: Wiley (Inter Science), 1968.

[4] J. Vitayapirak, "A corpus for a dictionary of computer science," presented at the 13th World Congress of Applied Linguistics (AILA 2002): Applied Linguistics in the 21st Century: Opportunities for Innovation and Creativity, Singapore: Suntec City, 2002.
[5] A. Coxhead, “A new academic word lis," TESOL Quarterly, vol. 34, no. 2, pp. 213-238, 2000.

[6] D. Crystal, An Encyclopaedia Dictionary of Language and Languages, Cambridge: Cambridge University Press, 1992.

[7] P. Mallikamas, Application of Corpora in Language Teaching, Thai TESOL BULLETIN, pp. 1-17, 1999.

[8] M. Scott, Oxford Word Smith Tools, Oxford: Oxford University Press, 2012.

[9] P. Nation. (2005). Range program with GSL and AWL. [Online]. Available: http://www.victoria.ac.nz/lals/about/staff/paul-nation

[10] L. Anthony. (2014). AntConc (Windows, Macintosh OS X, and Linux) build 3.4.3. [Online]. Available: http://www.laurenceanthony.net/software.html

[11] J. Vitayapirak, "A Corpus-based approach to ESP lexicography: The case study of English for Thai computer science students," PhD. thesis, Macquarie University, 2001.

Nantakarn Imphong was born on November 1, 1976 in Chaiyaphum, Thailand. In 2000, he graduated from Ramkhamhaeng University. He had received his bachelor degree in the field of arts (English). Then in 2010 he got a master degree in the field of education (guidance) from Sukhothai Thammathirat Open University, Thailand. At present, he is a Thai government English teacher at Minburi Technical College, Bangkok Thailand. His research interests include corpus, lexicography, and English teaching.

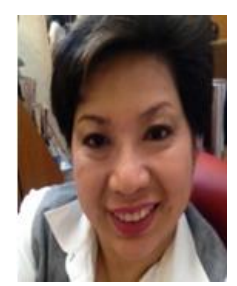

Jirapa Vitayapirak works at the Department of Applied Arts (English), Faculty of Industrial Education, King Mongkut's Institute of Technology Ladkrabang, Thailand. In 1986, she got a M.A. degree in applied linguistics, King Mongkut's University of Technology Thonburi, Thailand. In 2001, she got a Ph.D. degree in linguistics, from Macquarie University, Australia.

In 1996 she was the associate dean for academic affairs, Faculty of Faculty of Industrial Education, King Mongkut's Institute of Technology Ladkrabang. Her research interests are corpus lexicography, ESP, ELT and terminology. In 2008 to 2009 she had been the president of the Asian Association for Lexicography (ASIALEX). 